\title{
Definition of Acute Respiratory Distress Syndrome in Plateau of Xining,Qinghai: Verification of Berlin Definition Plateau Criteria
}

\author{
Xiaoqin Liu \\ Qinghai University \\ Chun Pan \\ Southeast University Zhongda Hospital \\ Li-Ning Si \\ Qinghai University Affiliated Hospital \\ Shijun Tong \\ Qinghai University Affiliated hospital \\ Yi Niu \\ Qinghai University Affiliated Hospital \\ Haibo Qiu \\ Southeast University Zhongda Hospital \\ Gan Guifen ( $\square$ xzhd1991@163.com ) \\ Affiliated Hospital of Qinghai University
}

\section{Research}

Keywords: Acute respiratory distress syndrome , High altitude, Berlin Definition

Posted Date: October 26th, 2020

DOl: https://doi.org/10.21203/rs.3.rs-91449/v1

License: () (i) This work is licensed under a Creative Commons Attribution 4.0 International License. Read Full License 


\section{Abstract}

\section{Background}

Acute respiratory distress syndrome $\mathbb{A} \mathrm{ARDS} \rrbracket$ is a common respiratory critical illness. The high altitude hypoxic environment has a great influence on its occurrence and development. Now we lack clear diagnostic definition of high altitude acute respiratory distress syndrome.To verify the application value of Berlin Definition plateau criteria of Acute Respiratory Distress Syndrome in Xining, Qinghai ( $2261 \mathrm{~m}$ ).

\section{Methods}

Retrospective analysis of the clinical data of ARDS patients admitted to the Department of Critical Care Medicine of the Affiliated Hospital of Qinghai University from January 2018 to December 2018. The severity was divided according to the Berlin definition, the plateau standard, and the Zhang standard, and the differences of three standards were compared.

\section{Results}

In this study, 512 patients with mechanical ventilation were selected. 229 patients who met the criteria of Berlin Definition plateau criteria , including 107 patients with mild ARDS (46.72\%), 84 moderate patients (36.68\%) and 38 severe ARDS patients (16.59\%). Among 253 meet Berlin definition patients, $49(19.77 \%)$ were mild,148(58.50\%) were moderate,and 56 (22.13\%) were severe ARDS. There are 204 patients that meet Zhang criteria, among the 204 enrolled patients, $87(42.65 \%)$ were ALI and 117(57.35\%) were ARDS. The AUROC of the Berlin Definition, the Plateau criteria and Zhang criteria were 0.6675 (95\% Cl 0.5866-0.7484), 0.6216 (95\% Cl 0.5317-0.7116) and 0.6050 (95\% Cl 0.5084-0.7016).

\section{Conclusion}

For Xining, Qinghai, the Berlin Definition Plateau oxygenation index correction criteria can distinguish the severity of ARDS , but it needs to be enlarged and confirmed by multicenter clinical studies.

\section{Introduction}

Acute respiratory distress syndrome (ARDS) is a severe disease, which has received much attention due to high mortality (35\%-40\%) ${ }^{(1)}$. The Berlin Definition of ARDS which was proposed in $2012^{(2)}$, now is used to diagnose the ARDS from the onset time, the source of pulmonary edema, and the chest X-ray, and stratify according to the $\mathrm{PO}_{2} / \mathrm{FiO}_{2}$.

Qinghai-Tibet Plateau which is an average elevation exceeding 4,500 metres, is the world's highest and largest plateau, with an area of 2,500,000 square kilometers. There are nearly 6 million people living in Qinghai Province and 3 million people living in the high-altitude area.

Due to the acute and chronic hypoxia of the plateau, ARDS patients have special pathophysiological changes and clinical manifestations ${ }^{(3)}$. If the definition of ARDS is completely followed in the plain area, it must lead to error treatment in plateau. Zhang et al. proposed that the diagnostic criteria of ALI/ARDS at high altitudes in western China in 2001, however, after the Berlin Definition was proposed, the ARDS plateau definition should be updated ${ }^{(4)}$.

For the plateau area, Berlin Definition indicate that in areas with altitudes above 1000 meters, the $\mathrm{PO}_{2} / \mathrm{FiO}_{2}$ should be calculated according to the correction formula: $\left[\mathrm{PaO}_{2} / \mathrm{FiO}_{2} \times(\text { atmospheric pressure } / 760)\right]^{(2)}$, however, there is no clear evidence to prove whether the "Berlin Plateau Definition" is suitable for ARDS patients in high-altitude area. The objectives were to update the definition using new data (epidemiological, physiological, and clinical trials) to address the current limitations of the AECC definition and explore other defining variables.

\section{Methods}

\section{Study design}

The study was a single-center, retrospective, observational study. In order to verify the application value of Berlin Definition plateau criteria of ARDS in Xining, Qinghai $(2261 \mathrm{~m})$.Because the data would be received in de-identified form (non-human subjects research), the hospital institutional review board waived the need for informed consent and approved the study.The trial was registered at clinicaltrials.gov (NCT04199650).

\section{Definition}

The oxygenation index classification criteria of Berlin Definition are as follows: mild :200mmHg $<\mathrm{PaO}_{2} / \mathrm{FiO}_{2} \leq 300 \mathrm{mmHg}, \mathrm{ARDS}_{100 \mathrm{mmHg}}<\mathrm{PaO}_{2} / \mathrm{FiO}{ }_{2}$ $<200 \mathrm{mmHg}$, ARDS: $\mathrm{PaO}_{2} / \mathrm{FiO}_{2} \leq 100 \mathrm{mmHg}$

The Berlin Definition Plateau Criteria (following as Plateau criteria):all patients meet the Berlin Definition except the oxygenation index. The oxygenation index is calculated according to the plateau correction formula: $\left[\mathrm{PaO}_{2} / \mathrm{FiO}_{2}\right.$ (barometric pressure/760)]. Berlin Definition Plateau criteria combined with Xi'ning atmospheric pressure $(581 \mathrm{mmHg})$, Plateau Criteria of ARDS severity are as follows: mild: $153 \mathrm{mmHg}<\mathrm{PaO}_{2} / \mathrm{FiO}_{2} \leq 230 \mathrm{mmHg}, \mathrm{moderate}$ $: 76 \mathrm{mmHg}<\mathrm{PaO}_{2} / \mathrm{FiO}_{2} \leq 153 \mathrm{mmHg}$, severe: $\mathrm{PaO}_{2} / \mathrm{FiO}_{2} \leq 76 \mathrm{mmHg}$. 
The diagnostic criteria of ALI/ARDS at high altitudes in western China (following as Zhang criteria ) proposed by Zhang et al are classified as ALI or ARDS according to the oxygenation index criteria of altitude $(2200 \mathrm{~m})$ in Xining while meeting the diagnostic criteria of AECC. Patients with oxygenation index $\leq 150 \mathrm{mmHg}$ were diagnosed as ARDS When ALI, oxygenation index was between 150 and $200 \mathrm{mmHg}$.

\section{Study population}

Recruited mechanical ventilation patients who entered Department of Intensive Medicine of the Affiliated Hospital of Qinghai University within 12 months QJanuary 2018 to December 2018). They must meet the diagnostic criteria of the Berlin Definition or Plateau Criteria or Zhang criteria or both. We excluded those younger than 18 years and those with ICU length of stay $<24 \mathrm{~h}$.

\section{Data collection}

For every enrolled patient, clinical data were assessed to detect whether they fulfilled either the diagnostic criteria of the Berlin Definition or Berlin Definition Plateau Criteria or Diagnostic Criteria of ALI/ARDS at high altitudes in Western China or both. Demographic data, underlying diseases and the risk factors of ARDS, Acute Physiology and Chronic Health Evaluation (APACHE) II score are recorded during the first 24 hours of ICU admission . FiO ${ }_{2}$, blood gases $\llbracket$ severity of illness $\llbracket$ were recorded on first day. The first day was defined as the first day which the patients fulfilled the ARDS or ALI criteria. Given the difficulty of comparing non-invasive ventilation settings with invasive modes, we excluded patients with non-invasive ventilation from the analysis of ventilator management. intervention and treatment during ICU stay, and patient outcome were recorded.

\section{Outcome measures}

The primary outcome measures were ICU mortality,28-days mortality and 28-day mechanical ventilation free days. The secondary outcome measures were mechanical ventilation length, ICU and hospital length of stay.

\section{Statistical analysis}

Normally distributed data are presented as mean \pm SD and non-normally distributed data are presented as median (IQR). P values for categorical variables were calculated with the $\chi^{2}$ test; $p$ values for continuous variables were estimated with the t test, Mann-Whitney, analysis of variance, or Kruskal-Wallis, depending on the distribution and number of variables. The receiver operating curve statistical analyses were performed by using Graphpad Prism for Windows version 8.1 and other statistical tests were performed with SPSS for Windows version 19.0 . Statistical significance was assessed at the 2-sided $\mathrm{p}<0.05$ level.

\section{Results}

Since the patients are from highland area,we analyzed the patients enrolled and characteristics, blood gas and mechanical ventilation data based on the Berlin definition plateau criteria .

\section{Patients enrolled and characteristics}

There was 512 with invasive mechanical ventilation admissions during the study period. Of this group, 253 patients met the Berlin definition, 229 with ARDS by Berlin Definition Plateau Criteria and 204 patients meet the Zhang criteria.( figure 1)

\section{General Information}

There were 229 patients that meet plateau criteria, 107(46.72\%) were mild ARDS, 84(36.68\%) were moderate ARDS and 38(16.59\%) were severe ARDS.

Patients with severe ARDS have fewer chronic hepatic dysfunctions than mild to moderate patients $(\mathrm{P}=0.017)$, APACHE II scores at presentation were slightly higher for patients with severe ARDS $(P<0.001)$; the most common risk factors were infection, pneumonia, aspiration and trauma.

(TABLE 1).TABLE 1 General Information of 229 meet Berlin Definition Plateau Criteria 


\begin{tabular}{|c|c|c|c|c|}
\hline & Mild & Moderate & Severe & $P$ values \\
\hline $\mathrm{No} \% \%$ & $107 \rrbracket 46.72 \% \rrbracket$ & $84 \llbracket 36.68 \% \rrbracket$ & $38 ه 16.59 \% \rrbracket$ & \\
\hline Age (years, $\pm s$ ) & $50.45 \pm 15.40$ & $56.85 \pm 16.83$ & $59.05 \pm 14.64$ & 0.290 \\
\hline Male $(n, \%)$ & $74(69.16 \%)$ & $55(65.47 \%)$ & $26(68.42 \%)$ & 0.859 \\
\hline \multicolumn{5}{|l|}{ Source of entry ICU $(n, \%)$} \\
\hline Surgery & $39(36.45 \%)$ & $40(47.62 \%)$ & $10(26.32 \%)$ & 0.064 \\
\hline Internal Medicine & $10(9.35 \%)$ & $10(11.90 \%)$ & $12(31.58 \%)$ & 0.003 \\
\hline Emergency & $58(54.21 \%)$ & $34(40.47 \%)$ & $16(42.11 \%)$ & 0.134 \\
\hline \multicolumn{5}{|l|}{ ARDS risk factors $(n, \%)$} \\
\hline Pneumonia & $16(14.95 \%)$ & $18(21.43 \%)$ & $8(21.05 \%)$ & 0.463 \\
\hline Infection & $37(34.58 \%)$ & $35(41.67 \%)$ & $11(28.95 \%)$ & 0.355 \\
\hline Misprision & $15(14.02 \%)$ & $12(14.29 \%)$ & $5(13.16 \%)$ & 0.986 \\
\hline Trauma & $22(20.56 \%)$ & $15(17.86 \%)$ & $4(10.53 \%)$ & 0.383 \\
\hline \multicolumn{5}{|l|}{ Basic diseases $(n, \%)$} \\
\hline Hypertension & $33(30.84 \%)$ & $27(32.14 \%)$ & $8(21.05 \%)$ & 0.434 \\
\hline Diabetes mellitus & $15(14.02 \%)$ & $15(17.86 \%)$ & $1(2.63 \%)$ & 0.073 \\
\hline Chronic pulmonary disease & $14(13.08 \%)$ & $21(25.00 \%)$ & $6(15.79 \%)$ & 0.096 \\
\hline Chronic cardiac insufficiency & $25(23.36 \%)$ & $25(29.76 \%)$ & $9(23.68 \%)$ & 0.574 \\
\hline Chronic renal dysfunction & 19(17.76\%) & $15(17.86 \%)$ & $2(5.26 \%)$ & 0.153 \\
\hline Chronic liver dysfunction & $29(27.10 \%)$ & $17(20.24 \%)$ & $2(5.26 \%)$ & 0.017 \\
\hline APACHE II score & $12.45 \pm 5.11$ & $13.24 \pm 5.28$ & $17.55 \pm 5.52$ & $<0.001$ \\
\hline $\mathrm{PaO}_{2} / \mathrm{FiO}_{2}( \pm \mathrm{s})$ & $183.49 \pm 20.04$ & $118.15 \pm 20.97$ & $52.31 \pm 12.39$ & $<0.001$ \\
\hline $\mathrm{pH}( \pm \mathrm{s})$ & $7.37 \pm 0.31$ & $7.29 \pm 0.81$ & $7.37 \pm 0.11$ & 0.572 \\
\hline $\mathrm{PaCO}_{2}(\mathrm{mmHg}, \pm \mathrm{s})$ & $36.52 \pm 18.21$ & $41.17 \pm 18.26$ & $42.10 \pm 12.03$ & 0.098 \\
\hline $\mathrm{PaO}_{2}(\mathrm{mmHg}, \pm \mathrm{s})$ & $82.25 \pm 35.70$ & $66.2 \pm 22.92$ & $43.86 \pm 14.28$ & $<0.001$ \\
\hline $\mathrm{FiO}_{2}(\%, \pm \mathrm{s})$ & $63.92 \pm 22.37$ & $71.87 \pm 21.41$ & $89.47 \pm 15.93$ & $\varangle 0.001$ \\
\hline PEEP $\left(\mathrm{cmH}_{2} \mathrm{O}, \pm \mathrm{s}\right)$ & $5.11 \pm 0.86$ & $5.36 \pm 1.59$ & $5.26 \pm 0.86$ & 0.358 \\
\hline Lac (mmol/L, median IQR) & $1.90(1.30-3.40)$ & $2.40(1.40-4.85)$ & $3.30(2.05-5.63)$ & 0.030 \\
\hline
\end{tabular}

APACHE II, Acute Physiology and Chronic Health Evaluation Il; $\mathrm{PaO}_{2}$, partial pressure of arterial oxygen; $\mathrm{FiO}_{2}$, fraction of inspired oxygen; $\mathrm{PaO}_{2}$, arterial oxygen partial pressure; $\mathrm{PaCO}_{2}$, arterial carbon dioxide partial pressure; $\mathrm{FiO}_{2}$, fraction of inspired oxygen; PEEP, positive end-expiratory pressure.Lac, lactic.

\section{Blood gas and Mechanical Ventilation Practice}

In the indicators of $\mathrm{pH}$ and arterial carbon dioxide partial pressure $\left(\mathrm{PaCO}_{2}\right)$ the three groups have similar values. Arterial partial pressure of oxygen $\left(\mathrm{PaO} \mathrm{O}_{2}\right)$ and $\mathrm{PaO}_{2} / \mathrm{FiO}_{2}$ significantly decreased with increasing ARDS severity $(\mathrm{P}<0.001)$, and increasing severity of ARDS was associated with higher lactate (Lac) values (TABLE 1).

The ventilator parameters were recorded during the first 24 hours which the patients fulfilled the Plateau criteria (TABLE 1). Most doctors use lung protective ventilation strategies. In order to prevent ventilator-related lung injury, PEEP have not increased with the severity of ARDS.However囚the oxygen concentration fraction of inhalation $\left(\mathrm{FiO}_{2}\right)$ was associated with a worse prognosis and the difference was statistically significant $(\mathrm{P}<0.001)$.

\section{Outcomes in Patients with ARDS}

\section{The Berlin definition plateau criteria}

Among the 229 meet Berlin Definition Plateau Criteria patients ,107(46.72\%) patients diagnosed with mild ARDS , 84(36.68\%) patients meet criteria for moderate ARDS, and 38(16.59\%) were severe ARDS. ICU mortality increased with stages of ARDS from mild $17.76 \%$ to moderate $21.43 \%$ to severe $47.37 \%$. 
28-days mortality increased with worsen of ARDS (mild 23.36\% VS moderate 44.05\% VS severe 63.16\%) (P<0.001). Median (IQR) 28-days ventilator free days declined with stages of ARDS from mild 21.42(3.75-26.50) days to moderate $16.53(0.00-24.28)$ days to severe $0.0(0.00-16.02)$ days $(P<0.001)$.

Median (IQR) duration of mechanical ventilation in survivors slightly increased with stages of ARDS from mild 3.88(1.04-9.13) days to moderate 4.46 (1.40-9.45) days to severe 5.11 (2.73-11.85)days, but the difference was not statistically significant $(P=0.132)$. Differences of between ICU length of stay and the hospital length of stay across categories of Berlin Definition (mild, moderate, and severe) were statistically significant.

\section{The Berlin definition}

253 patients meet the Berlin definition, of whom 49(19.37\%) were mild,148(58.50\%) were moderate and 56(22.13\%) were severe ARDS.The ICU mortality of mild, moderate and severe ARDS patients were $6.12 \%, 18.92 \%, 42.86 \%,(\mathrm{P}<0.001)$. With worsen of ARDS, 28-days mortality increases(mild 6.12\% VS moderate $33.11 \%$ VS severe $60.71 \%$ ) and median (IQR)28-days ventilator free days drops, which from mild 26.17 (20.00-27.21) days , moderate ARDS 18.73 (0.00-25.30) days to severe ARDS 0.00(0.00-18.26) days.

\section{Diagnostic Criteria of ALI/ARDS at high altitudes in Western China}

There are 204 patients that meet Zhang criteria, among the 204 enrolled patients, 87(42.65\%) were ALI and 117(57.35\%) were ARDS. The ICU mortality was ALI 18.39\% VS ARDS 30.77\%, ( $P=0.045)$, and the 28 days mortality ARDS (51.28\%) was higher than ALI ( $26.44 \%),(P<0.001) .28$-days ventilator free days median from ALI [19.50 (0.00-26.04)] to ARDS [4.21(0.00-23.31)] $(\mathrm{P}=0.03)$. There is no statistical difference between the ICU length of stay, duration of invasive ventilation and hospital length of stay. ( TABLE 2)

TABLE 2 Comparison of three criteria outcomes

\begin{tabular}{|c|c|c|c|c|c|c|c|c|c|c|c|}
\hline & \multicolumn{4}{|c|}{ Berlin Definition (253 cases) } & \multicolumn{4}{|c|}{ Plateau criteria (229 cases) } & \multicolumn{3}{|c|}{ Zhang criteria (204 cases $\rrbracket$} \\
\hline & Mild & Moderate & Severe & $\begin{array}{l}P \\
\text { values }\end{array}$ & Mild & Moderate & Severe & $\begin{array}{l}P \\
\text { values }\end{array}$ & ALI & ARDS & $\begin{array}{l}P \\
\text { values }\end{array}$ \\
\hline $\mathrm{No}(\%)$ & 49(19.37) & $148(58.50)$ & $56(22.13)$ & & $107(46.72)$ & $84(36.68)$ & $38(16.59)$ & & $87(42.65)$ & 117(57.35) & \\
\hline $\begin{array}{l}\text { ICU } \\
\text { mortality: } \\
\text { NO(\%) }\end{array}$ & $3(6.12)$ & 28(18.92) & $24(42.86)$ & $\varangle 0.001$ & 19(17.76) & $18(21.43)$ & 18(47.37) & 0.001 & 16(18.39) & $36(30.77)$ & 0.045 \\
\hline $\begin{array}{l}\text { 28-days } \\
\text { mortality } \\
\text { No(\%) }\end{array}$ & $3(6.12)$ & $49(33.11)$ & $34(60.71)$ & $₫ 0.001$ & $25(23.36)$ & $37(44.05)$ & $24(63.16)$ & $\bowtie 0.001$ & $23(26.44)$ & $60(51.28)$ & $₫ 0.001$ \\
\hline \multirow{2}{*}{$\begin{array}{l}\text { 28-days } \\
\text { ventilator } \\
\text { free days } \\
\text { median } \\
\text { (IQR) }\end{array}$} & 26.17 & 18.73 & 0.0 & $\otimes 0.001$ & 21.42 & 16.53 & 5.60 & $\varangle 0.01$ & 19.50 & 4.21 & 0.03 \\
\hline & $\begin{array}{l}(20.00- \\
27.21)\end{array}$ & $\begin{array}{l}(0.00- \\
25.30)\end{array}$ & $\begin{array}{l}(0.00- \\
18.26)\end{array}$ & & $\begin{array}{l}(3.75- \\
26.50)\end{array}$ & $\begin{array}{l}(0.00- \\
24.28)\end{array}$ & $\begin{array}{l}(0.00- \\
16.02)\end{array}$ & & $\begin{array}{l}(0.00- \\
26.04)\end{array}$ & $\begin{array}{l}(0.00- \\
23.31)\end{array}$ & \\
\hline \multirow{2}{*}{$\begin{array}{l}\text { ICU length } \\
\text { of stay, d, } \\
\text { median } \\
\text { (IQR) }\end{array}$} & 6.00 & 8.71 & 6.69 & 0.024 & 7.67 & 8.23 & 7.69 & 0.929 & 8.08 & 7.79 & 0.246 \\
\hline & $\begin{array}{l}(2.23- \\
12.32)\end{array}$ & $\begin{array}{l}(4.63- \\
18.10)\end{array}$ & $\begin{array}{l}(3.53- \\
14.18)\end{array}$ & & $\begin{array}{l}(3.67- \\
14.92)\end{array}$ & $\begin{array}{l}(3.71- \\
16.96)\end{array}$ & $\begin{array}{l}(4.30- \\
14.77)\end{array}$ & & $\begin{array}{l}(4.63- \\
16.42)\end{array}$ & $\begin{array}{l}(3.63- \\
15.17)\end{array}$ & \\
\hline \multirow{2}{*}{$\begin{array}{l}\text { Duration } \\
\text { of invasive } \\
\text { ventilation, } \\
\text { d, median } \\
\text { (IQR) }\end{array}$} & 1.79 & 4.75 & 4.23 & 0.003 & 3.88 & 4.46 & 5.11 & 0.132 & 5.08 & 4.67 & 0.945 \\
\hline & $\begin{array}{l}(0.73- \\
4.98)\end{array}$ & $\begin{array}{l}(1.50- \\
10.62)\end{array}$ & $\begin{array}{l}(2.16- \\
9.92)\end{array}$ & & $(1.04-9.13)$ & $\begin{array}{l}(1.40- \\
9.45)\end{array}$ & $\begin{array}{l}(2.73- \\
11.85)\end{array}$ & & $\begin{array}{l}(1.46- \\
9.83)\end{array}$ & $\begin{array}{l}(2.15- \\
10.63)\end{array}$ & \\
\hline \multirow{2}{*}{$\begin{array}{l}\text { Hospital } \\
\text { length of } \\
\text { stay, d, } \\
\text { median } \\
\text { (IQR) }\end{array}$} & 24.00 & 22.00 & 16.00 & 0.001 & 23.00 & 18.50 & 18.00 & 0.036 & 23.00 & 18.00 & 0.059 \\
\hline & $\begin{array}{l}(19.00- \\
38.00)\end{array}$ & $\begin{array}{l}(13.25- \\
35.75)\end{array}$ & $\begin{array}{l}(6.00- \\
25.75)\end{array}$ & & $\begin{array}{l}(14.00- \\
37.00)\end{array}$ & $\begin{array}{l}(9.25- \\
30.00)\end{array}$ & $\begin{array}{l}(8.00- \\
26.00)\end{array}$ & & $\begin{array}{l}(14.00- \\
38.00)\end{array}$ & $\begin{array}{l}(9.00- \\
29.50)\end{array}$ & \\
\hline
\end{tabular}

The AUROC of the Berlin Definition, the Plateau criteriaand Zhang criteria were 0.6675 (95\% CIPower0.5866-0.7484), 0.6216 (95\% CIPower0.5317-0.7116) and 0.6050 (95\% CIPower0.5084-0.7016). There was no significant difference among the three groups.

\section{Discussion}

The main manifestation of ARDS is stubborn hypoxemia due to the pathophysiological changes of decreased lung volume, decreased compliance and decreased ratio of ventilatory blood flow in it ${ }^{(5)}$. Although more and more clinical studies in recent years have confirmed that some biomarkers are associated with ARDS, there is no evidence that they can be used in the diagnosis of ARDS $(6,7)\{$ Steinberg, 1994 \#70;Probst, 2020 \#78\}. The diagnosis of ARDS still focuses on the function of the lung, including the time of onset, oxygenation index and imaging findings ${ }^{(8)}$. Oxygenation index is the most important method to judge the severity of ARDS ${ }^{(9)}$. However, as mentioned earlier, the high altitude area has the characteristics of low oxygen pressure, strong radiation, cold climate and so on ${ }^{(10)}$. With the increase of altitude, the atmospheric pressure and the partial pressure of inhaled oxygen decrease 
obviously ${ }^{(3)}$. The low oxygen environment is one of the greatest effects on the human body in the high altitude area(11). Some studies have pointed out that the arterial blood oxygen partial pressure of healthy adults at high altitude is significantly lower than that of healthy adults of the same age group in the plain area ${ }^{(12)}$. Acute and chronic hypoxia at high altitude can induce a variety of diseases and affect the quality of life and working ability of people at high altitude. People living at high altitude for a long time have different tolerance to hypoxic environment, resulting in pathophysiological changes of ARDS patients in high altitude area, which are different from those in plain area(13).

Studies have confirmed that high altitude acute respiratory distress syndrome is characterized by hypoxemia that is not easy to correct, pulmonary artery pressure is significantly increased, and the inflammatory response is more serious than the plain. We need to put forward the plateau criteria.

According to the AECC criteria, some mild patients are diagnosed as ALI, which makes clinicians lack awareness of this subgroup and fail to give appropriate support and treatment. In 2001, Zhang et al put forward the diagnostic criteria of ALI/ARDS in high altitude areas of western China on the basis of AECC diagnostic criteria. Therefore, we need to update the Zhang criteria ${ }^{(4)}$. From this study, we can know that when diagnosing ARDS patients in Xining, Qinghai Province according to the diagnostic criteria of ALI/ARDS in high altitude areas of western China, the case fatality rate of ARDS is significantly lower than that of ARDS in China and other parts of the world. This may be due to the fact that the criteria excludes some patients with mild ARDS, that is, oxygen and index between $200-253 \mathrm{mmHg}$, resulting in no significant difference between groups.

In recent years, the case fatality rate and mortality rate of large-scale ARDS epidemiological survey in the world vary greatly from region to region. 2016 LUNGSAFE study involving 50 countries and regions and 459 ICU shows that even though the case fatality rate of ARDS is different in different regions, the global case fatality rate of ARDS is still as high as $40 \%{ }^{(1)}$. In 2018 , Liu Ling and others completed the ARDS epidemiological survey of 20 ICU in China. In China, the ICU fatality rate of ARDS is about $32 \%$, and the hospital mortality rate of severe ARDS is as high as $60 \%(14)$.

In this study, in Xining, Qinghai, the ICU mortality of patients diagnosed as ARDS according to the plateau criteria for high altitude areas was $24.02 \%$, and the ICU mortality of mild, moderate and severe ARDS were $17.76 \%, 21.43 \%$ and $47.37 \%$, respectively. The 28 -days mortality was $37.56 \%$, $23.36 \%$ for mild, $44.05 \%$ for moderate, and $63.16 \%$ for severe ARDS. The results are similar to the results of international and domestic large-scale epidemiological studies of ARDS in recent years. In contrast, according to the Berlin criteria to classify the severity of ARDS in Xining, Qinghai, the ICU mortality of mild ARDS patients is only $6.12 \%$, which is significantly lower than that of epidemiological studies. At high altitude, the oxygen content and partial pressure of oxygen in the air were lower than those in the plain area, and when the partial pressure of oxygen $<300 \mathrm{mmHg}$ in patients at high altitude, there were no other serious pulmonary pathological changes, even if the patients had lung infiltration shadow and other characteristics consistent with the diagnostic criteria of ARDS, it could not be regarded as ARDS. When the Berlin Definition was included in patients according to $300 \mathrm{mmHg}$ criteria, false positives occurred, resulting in a significant reduction in mortality in the mild ARDS group.

This study preliminarily confirmed that the plateau criteria can be used to classify the severity of ARDS in Xining area of Qinghai Province. Zhang criteria may cause clinicians to fail to realize the seriousness of some patients, resulting in delay in diagnosis, while the application of Berlin criteria in high altitude areas may include a large number of patients who do not belong to ARDS, resulting in false positive and overtreatment.

This study also has some limitations: (1) This study is a single-center retrospective study, the sample size is small, the sample source is limited, resulting in the sample is not very representative, it still needs to be verified by multicenter clinical studies in the later stage. (2) According to the results of this study, the plateau criteria of ARDS in Xining, Qinghai, but it is not clear whether this criteria is applicable to other areas at the same altitude and other altitude areas, which still needs to be verified by later multicenter clinical trials. (3) As there is no other strong basis for the diagnosis of ARDS at present, the mortality is regarded as the main prognostic end point in this study, and in the process of disease progression, a variety of clinical intervention measures are often given, which may affect the prognosis of patients to a certain extent.(4) In the experiment, we observed that there is no difference in the setting of PEEP in different severity levels. The severe ARDS FiO 2 setting is higher. We cannot judge whether PEEP has an effect on the improvement of oxygenation index.

\section{Conclusion}

For Xining, Qinghai province, the Berlin definition Plateau criteria can distinguish the severity of ARDS in high-altitude areas, but it needs to be enlarged and confirmed by multicenter clinical studies.

\section{Declarations}

\section{Acknowledgements}

Not applicable

\section{Authors'contributions}

G.F. G, C.P and X.Q. L designed the study; Y.N and L.N. S were responsible for the data acquisition, S.J T and X.Q. L were responsible for the data analysis and interpretation; X.Q. L drafted the manuscript; all authors substantively revised and approved the submitted version of the manuscript.

\section{Funding}


Qinghai province scientific and technological achievements transformation project (2019-SF-133)

Environmental Medical Engineering Key Laboratory of the Ministry of Education Open Project $\ 2020 E M E 001 \rrbracket$

\section{Availability of data and materials}

The datasets used and/or analyzed during the current study are available from the corresponding author on reasonable request.

\section{Ethics approval and consent to participate}

Because the data would be received in de-identified form (non-human subjects research), the hospital institutional review board waived the need for informed consent and approved the study.

\section{Consent for publication}

Not applicable

\section{Competing interests}

All authors declare that there are no conflicts of interest for the submitted study.

\section{References}

1. Bellani G, Laffey JG, Pham T, Fan E, Brochard L, Esteban A, et al. Epidemiology, Patterns of Care, and Mortality for Patients With Acute Respiratory Distress Syndrome in Intensive Care Units in 50 Countries. Jama. 2016;315(8):788.DOI:10.1001/jama.2016.0291

2. Force ADT, Ranieri VM, Rubenfeld GD, Thompson BT, Ferguson ND, Caldwell E, et al. Acute respiratory distress syndrome: the Berlin Definition. JAMA. 2012;307(23):2526-33.DOI:10.1001/jama.2012.5669

3. Zimmerman GA, Crapo RO. Adult respiratory distress syndrome secondary to high altitude pulmonary edema. Western Journal of Medicine. 1980;133(4):335-7.DOI:doi:10.1001/archinte.140.12.1671

4. Zhang S, Lin S, Gao W, Liu H, Liu Y, Zhang D, et al. Report of the Consensus Conference on Diagnostic Criteria of ALI/ARDS at high altitudes in Western China. Intensive Care Medicine. 2014;27(9):1539-46.DOI:10.1007/s001340101052

5. Schuster DP. ARDS: Clinical lessons from the oleic acid model of acute lung injury. Am J Respir Crit Care Med. 1994;149(1):24560.DOI:10.1164/ajrccm.149.1.8111590

6. Fan E , Brodie D , Slutsky A S . Acute Respiratory Distress Syndrome: Advances in Diagnosis and Treatment[J]. Jama, 2018, 319(7):698710.DOI:10.1001/jama.2017.21907

7. Probst CK, Montesi SB, Medoff BD, Shea BS, Knipe RS. Vascular Permeability in the Fibrotic Lung. The European respiratory journal. 2020.DOI:10.1183/13993003.00100-2019

8. Ferguson ND, Fan E, Camporota L, Antonelli M, Anzueto A, Beale R, et al. Erratum to: The Berlin definition of ARDS: an expanded rationale, justification, and supplementary material. 2012;38(10).DOI:10.1007/s00134-012-2682-1

9. Sweeney RM, McAuley DF. Acute respiratory distress syndrome. The Lancet. 2016;388(10058):2416-30.

10. Richalet JP, Larmignat P, Poitrine E, Letournel M, Canou-Poitrine F. Physiological Risk Factors for Severe High-Altitude Illness A Prospective Cohort Study. Am J Respir Crit Care Med. 2011;185(2):192-8.DOI:10.1164/rccm.201108-13960C

11. Zhang S, Lu H, Gao W, Xu K, Li N, Lu G, et al. Posttraumatic or inflammatory acute respiratory distress syndrome on high altitude area: a retrospective analysis of 94 deaths due to ARDS/MOF. 1999;37(12):751-3.

12. Shang C, Wuren T, Ga Q, Bai Z, Guo L, Eustes AS, et al. The human platelet transcriptome and proteome is altered and pro-thrombotic functional responses are increased during prolonged hypoxia exposure at high altitude. Platelets. 2019:1-10.DOI:10.1080/09537104.2019.1572876

13. West JB. High-Altitude Medicine. American Journal of Respiratory and Critical Care Medicine. 2012;186(12):1229-37.DOI:10.1164/rccm.201207$1323 \mathrm{Cl}$

14. Liu L, Yang Y, Gao ZW, Li MQ, Mu XW, Ma XC, et al. Practice of diagnosis and management of acute respiratory distress syndrome in mainland China: a cross-sectional study.[J]. Journal of thoracic disease,2018,10(9).DOI:10.21037/jtd.2018.08.137

\section{Figures}




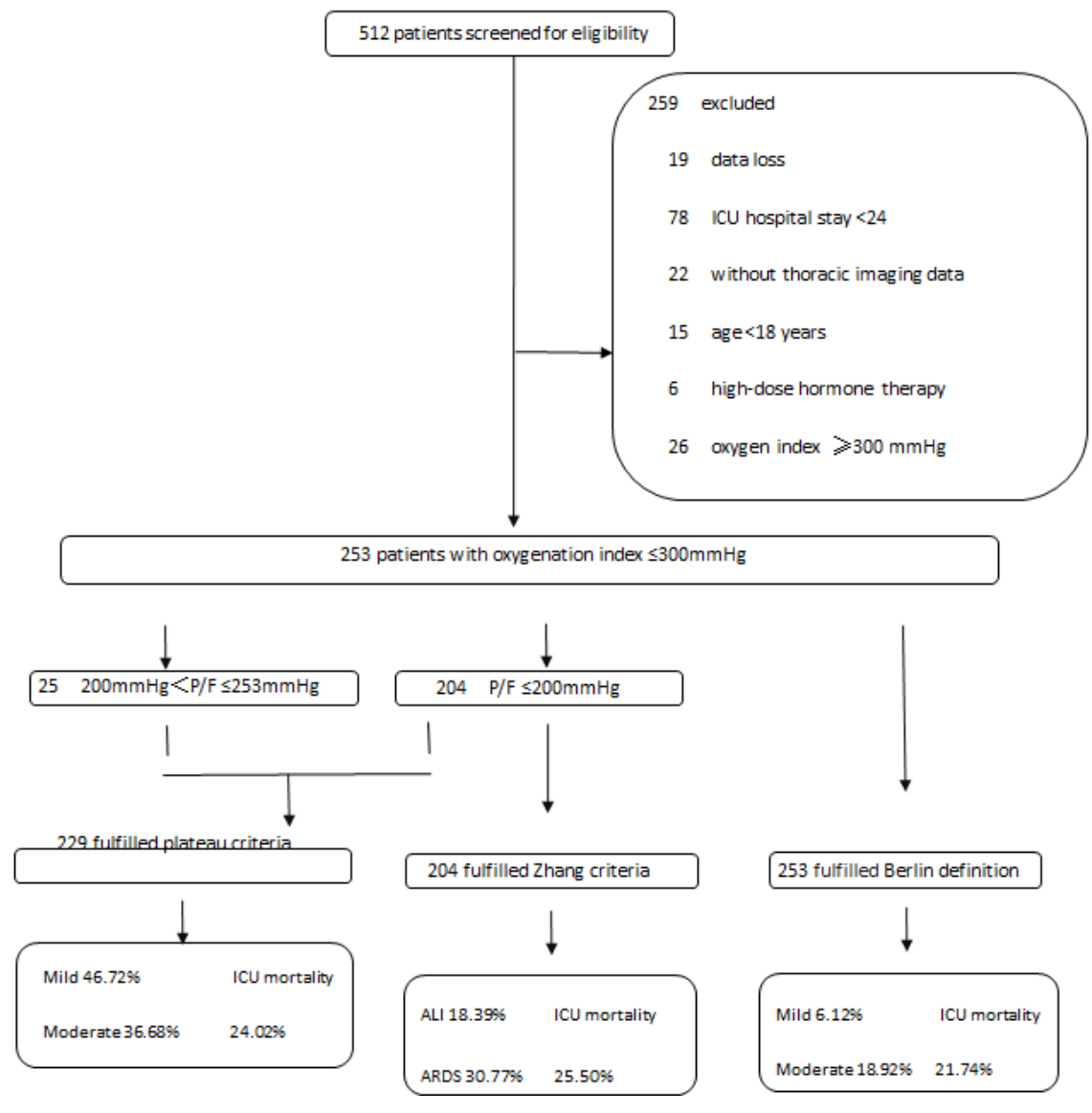

\section{Figure 1}

Flow chart of patient screening and entry

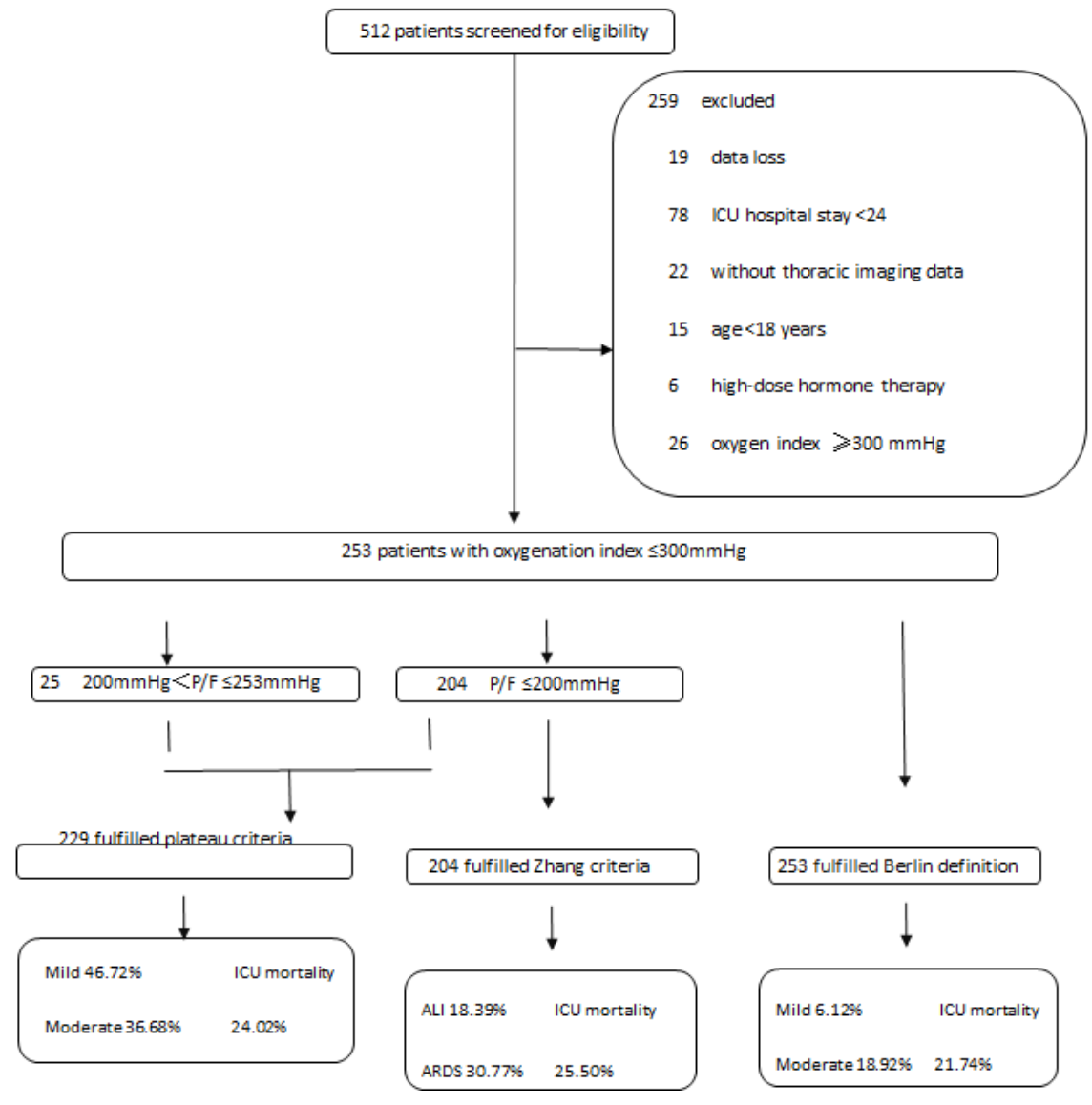

Page 8/9 
Figure 1

Flow chart of patient screening and entry

ROC curve: ROC of ROC curve data

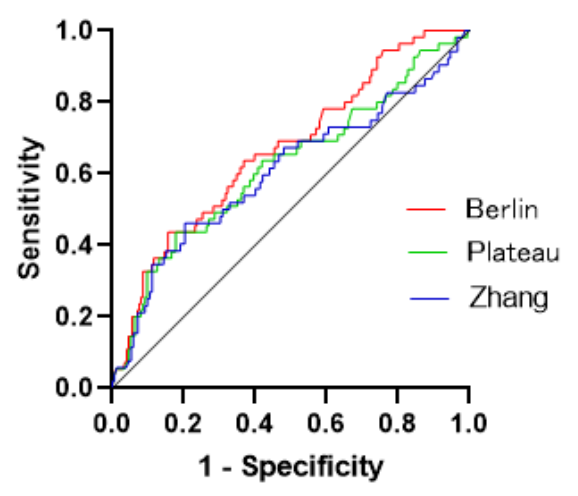

Figure 2

comparison of the area under the ROC curve of three different ARDS severity criteria ICU case fatality rate

\section{ROC curve: ROC of ROC curve data}

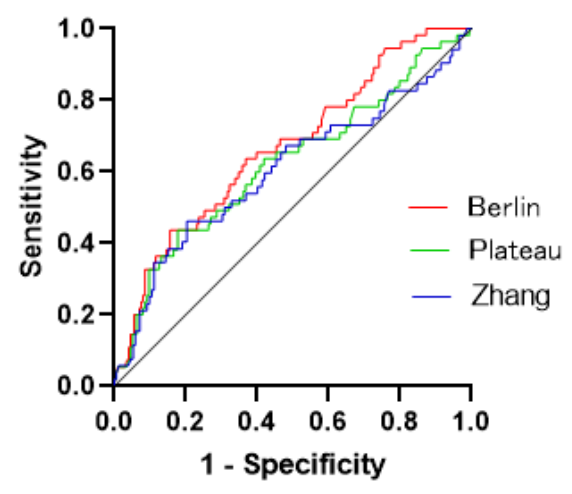

Figure 2

comparison of the area under the ROC curve of three different ARDS severity criteria ICU case fatality rate 